ARTICLE

DOI: $10.1038 / \mathrm{s} 41467-018-04147-2$

OPEN

\title{
Mimicking the surface and prebiotic chemistry of early Earth using flow chemistry
}

Dougal J. Ritson (1) ${ }^{1}$, Claudio Battilocchio (1D ${ }^{2,3}$, Steven V. Ley ${ }^{2} \&$ John D. Sutherland ${ }^{1}$

When considering life's aetiology, the first questions that must be addressed are "how?" and "where?" were ostensibly complex molecules, considered necessary for life's beginning, constructed from simpler, more abundant feedstock molecules on primitive Earth. Previously, we have used multiple clues from the prebiotic synthetic requirements of (proto)biomolecules to pinpoint a set of closely related geochemical scenarios that are suggestive of flow and semi-batch chemistries. We now wish to report a multistep, uninterrupted synthesis of a key heterocycle (2-aminooxazole) en route to activated nucleotides starting from highly plausible, prebiotic feedstock molecules under conditions which mimic this scenario. Further consideration of the scenario has uncovered additional pertinent and novel aspects of prebiotic chemistry, which greatly enhance the efficiency and plausibility of the synthesis.

\footnotetext{
${ }^{1}$ MRC Laboratory of Molecular Biology, Francis Crick Avenue, Cambridge Biomedical Campus, Cambridge CB2 OQH, UK. ${ }^{2}$ Department of Chemistry, University of Cambridge, Lensfield Road, Cambridge CB2 1EW, UK. ${ }^{3}$ Present address: Syngenta Crop Protection, Process Research, Schaffhauserstrasse 101, CH-4332 Stein, Switzerland. Correspondence and requests for materials should be addressed to D.J.R. (email: dritson@mrc-Imb.cam.ac.uk) or to J.D.S. (email: johns@mrc-Imb.cam.ac.uk)
} 
$\mathrm{T}$ he recalcitrant problem of the origin of life has many different facets, the most fundamental of all being the prebiotic synthesis of the minimum set of molecules which can lead to the first (living?) protocell. Intrinsically linked to this problem is the question of the physical place upon Earth where this synthesis took place, as the surrounding environment would have a direct bearing on the types of chemistry that were feasible ${ }^{1}$. This raises a question in itself-does one first consider a geochemical environment which one imagines could kick-start life and then (ideally) explore the chemistry which is possible within these bounds (geology first), or does one investigate a synthesis, which one hopes to be prebiotically plausible, and then try and fit that synthesis to an early Earth geological setting (chemistry first)?

An example of the geology first approach is deep-submarine vents, which have proven popular as a setting for the origin of life for many authors ${ }^{2-7}$. This popularity is due to several features of oceanic hydrothermal vents which appear to overlap with extant biology, and so a putative connection between abiotic and biotic worlds has been drawn. Over the last 30 years the model has undergone numerous refinements reaching a remarkable level of $\operatorname{detail}^{8-16}$. However, this would seem inconsistent with advances made in the laboratory, wherein only one productive synthetic experiment, conceivably consistent with vent conditions, has been reported-the conversion of $\mathrm{CO}$ and $\mathrm{MeSH}$ to (activated) acetate using $\mathrm{Fe}(\mathrm{Ni}) \mathrm{S}$ precipitates ${ }^{17}$, although these conditions might equally well have pertained to Earth's surface. Neither nucleotides, amino acids nor lipids have been synthesised under vent conditions.

An example of the chemistry first approach to the origin of life is the formose reaction (Supplementary Fig. 1). Discovered in 1861 by Butlerow ${ }^{18}$, this reaction has appealed to prebiotic chemists in the modern era for several decades ${ }^{19,20}$ due to the fact that higher sugars, including ribose $\mathbf{1}$, can be formed by heating aqueous formaldehyde 2 (a simple $\mathrm{C}_{1}$ feedstock molecule, $\mathrm{CH}_{2} \mathrm{O}$ ) with calcium hydroxide, $\mathrm{Ca}(\mathrm{OH})_{2}$. Although there are severe, inherent problems with the formose reaction, which have caused many to question its prebiotic relevance (full critiques of the formose reaction can be found elsewhere ${ }^{20,21}$ ), some have attempted to control the non-selective and destructive nature of the reaction by the addition of various minerals, e.g., silicate and borate $^{22,23}$. Initially this looks to be a logical step, but the additional demands now placed on the geochemical scenario must be met, and this has not proven possible to date (for a brief, in-depth discussion, see Supplementary Discussion). For example, Kim et al. attempted to use borate to direct the formose reaction to make and stabilise ribose en route to RNA. However, although borate stabilises ribose, it actually inhibits the formose reaction, and so eventually the authors resort to commencing from $\mathrm{C}_{3}$ sugars and formaldehyde $\mathbf{2}^{23}$. Although this did not afford ribose, it did produce erythro-branched and thero-branched pentoses, which it was proposed could form pentuloses via a molybdatecatalysed Bílik reaction. This was shown to take place at mildly acidic $\mathrm{pH}$ and (apparently) in the absence of borate. Whether or not the reaction would proceed in the presence of borate is likely a moot point, however, as the accumulation of significant concentrations of molybdenum, in its highest oxidation state, on early Earth has been deemed geologically implausible ${ }^{24}$. Thus, trying to shoehorn a geochemical scenario to fit a putative prebiotic synthesis would not appear to be a prudent strategy. Perhaps not surprisingly, taking an inflexible stance on chemistry or geology seems to place such demands on their respective counterparts, i.e., geological scenario or feasible chemistry, as to preclude progress.

Consequently, we have adopted a more flexible approach ${ }^{25}$, in which we first allowed the results of extensive chemical experimentation to loosely constrain geochemical conditions. We then explored other consequences of the inferred range of conditions on the synthetic chemistry and bootstrapped our way between chemistry and geology to optimise syntheses and further constrain the geochemical conditions. This led to the discovery of a chemical network that yielded activated pyrimidines, amino acids, phospholipid precursors and most of the components of the citric acid cycle ${ }^{26,27}$. Concomitantly, a picture of a geochemical environment unfolded which met the requirements of all reactions in the network, and seemed (to us at least) plausible. The geochemical scenario was dependent on schreibersite $\left((\mathrm{Fe}, \mathrm{Ni})_{3} \mathrm{P}\right)$, $\mathrm{HCN}$, hydrosulfide $\left(\mathrm{HS}^{-}\right)$, copper and ultraviolet light under post-impact conditions. The action of UV light on catalytic amounts of copper(I) allows efficient reduction of cyanohydrins by hydrated electrons $\left(\mathrm{e}^{-}(a q)\right)$ and/or $\mathrm{H}^{\bullet}$ to form various aldehydes with $\mathrm{HS}^{-}$being consumed as the stoichiometric reductant (Fig. 1$)^{26,27}$. In a more recent refinement of this reaction, we have found that the photochemical reduction of nitriles can be performed equally effectively with catalytic ferrocyanide $\left(\mathrm{Fe}\left(\mathrm{CN}_{6}\right)^{4}\right.$ $\left.{ }^{-}\right)$and bisulfite $\left(\mathrm{HSO}_{3}{ }^{-} \text {, Fig. } 1\right)^{28}$. The presence of $\mathrm{SO}_{2}$ on early Earth would appear to have been probable ${ }^{29,30}$, if, according to a recent calculation, only present at a low, constant atmospheric level ${ }^{31}$. However, it has been pointed out that during periods of increased geothermal activity, spikes in atmospheric $\mathrm{SO}_{2}$ concentrations would have been expected ${ }^{30,32}$. In any event, due to the high solubility of $\mathrm{SO}_{2}$ in water and the low $\mathrm{p} K_{\mathrm{a}}$ of sulfurous

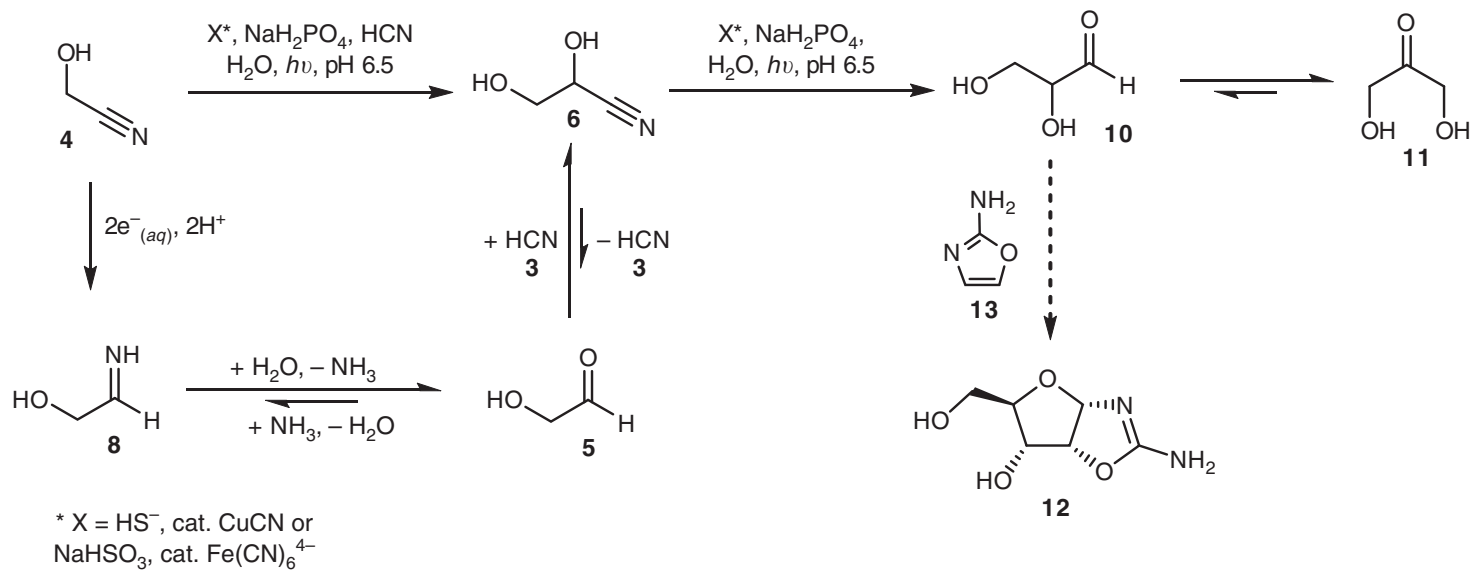

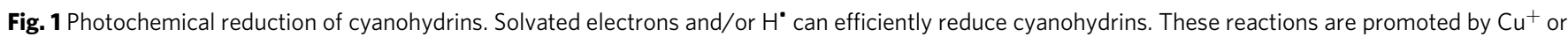
$\mathrm{Fe}^{2+}$ ions and a sulfurous stoichiometric reductant under UV irradiation 
acid, $\mathrm{HSO}_{3}{ }^{-}$could have been expected to be concentrated in ground water, even to the point of dryness ${ }^{33}$. Thus, given the presumed global abundance of $\mathrm{Fe}^{2+}$ ions, the $\mathrm{Fe}\left(\mathrm{CN}_{6}\right)^{4-} / \mathrm{HSO}_{3}{ }^{-}$ system may be a preferred means for achieving photoreductive homologation of hydrogen cyanide on early Earth. Interestingly, although atmospheric $\mathrm{SO}_{2}$ would be expected to absorb some UV light, it apparently permits the passage of light of the requisite wavelength to drive the photoreductive chemistry to the surface of Earth E $^{31,32}$.

Key to our geochemical scenario ${ }^{26,34}$ is the Late-Heavy Bombardment: iron-rich meteorites provided $\mathrm{FeS},(\mathrm{FeNi}) \mathrm{S}$ and (Fe, $\mathrm{Ni})_{3} \mathrm{P}$, the impact of falling bodies generated large quantities of atmospheric HCN 3 (the notation 3 is used to represent HCN and/or cyanide ion, $\mathrm{NC}^{-}$) through shock waves and electric discharge plasma ${ }^{35}$ and rain-in of 3 would have resulted in the corrosion of meteoritic metal inclusions providing cyanometallates, phosphate and $\mathrm{HS}^{-} / \mathrm{H}_{2} \mathrm{~S}$. In addition, the most abundant cyanometallate, ferrocyanide, when heated in the dry state, either from geothermal activity or further impact events, yields different products depending only on the nature of its counter ion (Fig. 2). Thus, the products from sodium/potassium, calcium and magnesium ferrocyanide are $\mathrm{Na} / \mathrm{KCN}$, calcium cyanamide + calcium carbide $\left(\mathrm{CaNCN}+\mathrm{CaC}_{2}\right)$ and magnesium nitride $\left(\mathrm{Mg}_{3} \mathrm{~N}_{2}\right)$, respectively - the exact feedstock molecules required to populate the protometabolic network previously reported ${ }^{26}$. Considering a landscape, distinct areas could have been rich in $\mathrm{NaCN}$ deposits or CaNCN deposits, based purely on the differences of abundance of $\mathrm{Na}^{+}$and $\mathrm{Ca}^{2+}$ ions in those regions at the time of evaporation of water before thermal metamorphosis. At a later juncture, after rainfall, streams or rivulets could start to flow, picking up substrates, reagents and catalysts in a sequence determined by the order in which the dry-state repositories were encountered. Photochemistry and dehydration/hydration steps could ensue, and upon confluence of the streams mixing and further reaction could take place. This geochemical situation would offer the type of mechanism required for sequential delivery of reagents to allow constructive and selective synthesis of all the (proto)biomolecules previously reported ${ }^{26}$. There are numerous variations to this scheme, for example, fluvial activity could bring the reagents from different areas to merge in a pool. The pool could undergo drying and rehydration and occasionally, in heavy rain, overflow, mixing the contents with other pools. Although all the required chemical steps had been demonstrated by us in the laboratory, some were still sceptical that the prebiotic relevance of the scheme was not

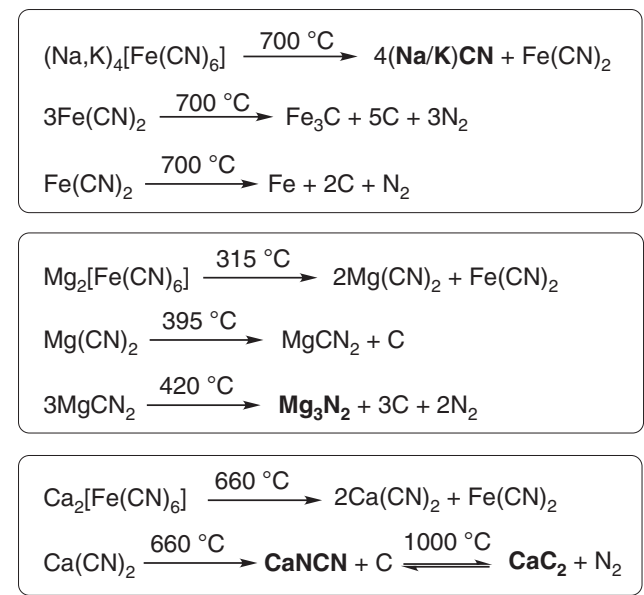

Fig. 2 Thermal metamorphosis of ferrocyanide salts. The products formed by heating ferrocyanide can be altered simply by exchanging the counterion of ferrocyanide and/or varying the temperature to which the salt is heated warranted as "the network cannot yet function in one pot without external interference" 36 . Notwithstanding the fact that the scheme is not meant to function in one pot, we wondered how we could best simulate the fluvial locale we envisaged without a hands-on approach. We were also keen to scrutinise the scenario again with a view to learning more ourselves. Below, we describe an uninterrupted synthesis of 2-aminooxazole from prebiotically plausible starting materials in an attempt to validate the plausibility of our geochemical scenario and the permissible prebiotic chemistry associated with that scenario. We found that bisulfite is an excellent all-round player, providing reducing power for the reduction of nitriles to aldehydes and the capacity to protect and concentrate the aldehydes, and therefore prebiotic amino acid and ribonucleotide precursors, yet, vitally, does not interfere with their syntheses.

\section{Results}

Evaluation of the photoreductive system. It soon became obvious that flow chemistry-a phrase we construe less stringently than others $\mathrm{do}^{37}$ - would be the ideal technique to simulate small streams flowing across Hadean/Archean Earth. Initial considerations of the optimal reductive system to be used $(\mathrm{CuCN} /$ $\mathrm{HS}^{-}+h v$ vs. $\left.\mathrm{Fe}(\mathrm{CN})_{6}{ }^{4-} / \mathrm{HSO}_{3}{ }^{-}+h v\right)$ were determined by compatibility with the flow system. $\mathrm{CuCN}$ is insoluble in water, as is the black precipitate that forms upon contact with $\mathrm{HS}^{-}$(presumably copper sulfides), and during the reduction of nitriles using this system, $\mathrm{HS}^{-}$is ultimately oxidised to $\mathrm{S}_{8}$, which precipitates from aqueous solution. While this is of no consequence when considering a stream on ancient Earth, solids are not welltolerated in flow chemistry due to the fine internal diameter of the tubing which is employed. Hence, we opted for the ferrocyanidebisulfite system, as all starting materials, products and byproducts are water soluble. As previously, we decided to begin the sequence from glycolonitrile $\mathbf{4}$ as the carbon source ${ }^{27}$. The presumed abundance of cyanide $\mathbf{3}$, whether produced terrestrially via thermal metamorphosis of ferrocyanide to give $\mathrm{K} / \mathrm{NaCN} 3$ (Fig. 2) or atmospherically as a result of electric discharge ${ }^{38}$ and impact synthesis ${ }^{35}$, should mean that a large amount of formaldehyde 2 (also produced atmospherically ${ }^{39}$ ) would encounter 3 resulting in glycolonitrile $\mathbf{4}$. Although the formation of $\mathbf{4}$ would be seen as detrimental to those wishing to exploit formaldehyde (vide supra) or HCN polymerisation chemistry, it affords the advantage of possessing a much higher boiling point than either of its components, i.e., glycolonitrile b.p. $=103^{\circ} \mathrm{C}(16 \mathrm{mmHg})^{40}$ cf. $\mathrm{HCN}$ b.p. $=26^{\circ} \mathrm{C}$ and $\mathrm{CH}_{2} \mathrm{O}$ b.p. $=-19^{\circ} \mathrm{C}$, which would allow its concentration (to some degree) in ground water. Thus, a concentration of $30 \mathrm{mM}$ of $\mathbf{4}$ did not seem to be an unreasonable starting point for investigation. We soon found promising conditions that gave excellent yields of glycolaldehyde 5 and its cyanide 6 and bisulfite 7 derivatives $(>60 \%)$ after $2 \mathrm{~h}$ of irradiation under batch conditions (Fig. 3 and Supplementary Fig. 2), which suggested that good yields of 5 would be accessible in the flow chemistry experiments.

As discussed (vide supra), the accumulation of $\mathrm{HSO}_{3}{ }^{-}$on the surface of Earth could have been extensive and even have resulted in dry bisulfite/sulfite-rich beds. Ferrocyanide and phosphate would have resulted from the corrosion of meteoritic schreibersite $^{26,3441,42}$, and could also be concentrated to dryness. Thus, in the first instance, we imagined a stream of glycolonitrile 4 meeting a stream of $\mathrm{NaHSO}_{3}, \mathrm{~K}_{4}\left[\mathrm{Fe}(\mathrm{CN})_{6}\right]$ and $\mathrm{NaH}_{2} \mathrm{PO}_{4}$, and the merged stream being exposed to sunlight. Of course, there are many variations of a theme one can think of that would result in a similar chemical system. For instance, a stream of $\mathbf{4}$ could run over a dry bed of $\mathrm{NaHSO}_{3}$, then a dry bed of $\mathrm{NaH}_{2} \mathrm{PO}_{4} / \mathrm{K}_{4}[\mathrm{Fe}$ $\left.(\mathrm{CN})_{6}\right]$, dissolving up the salts in the process. This sequence 


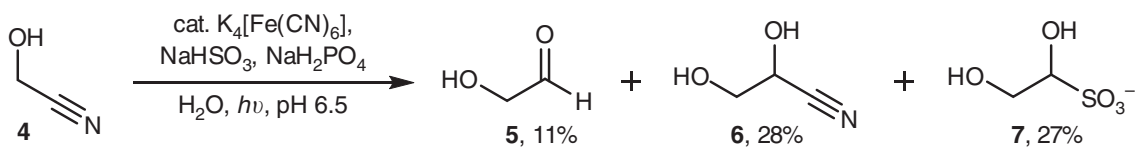

Fig. 3 Photochemical reduction of 4 using the $\mathrm{Fe}^{2+} / \mathrm{NaHSO}_{3}$ system. Typical conditions: glycolonitrile $\mathbf{4}(30 \mathrm{mM}), \mathrm{Na}_{2} \mathrm{SO}_{3}(50 \mathrm{mM}), \mathrm{NaH}_{2} \mathrm{PO}_{4}(100 \mathrm{mM})$ and $\mathrm{K}_{4}\left[\mathrm{Fe}(\mathrm{CN})_{6}\right](5 \mathrm{mM})$ in $\mathrm{H}_{2} \mathrm{O}: \mathrm{D}_{2} \mathrm{O}(9: 1)$, $\mathrm{pH}$ adjusted to 6.5 with degassed $\mathrm{HCl} / \mathrm{NaOH}$ and the solution was irradiated. Glyceronitrile 6 was presumed to be formed due to the liberation of cyanide in the work-up procedure, whereby paramagnetic $\mathrm{Fe}_{x}(\mathrm{CN})_{y} \mathrm{~L}_{z}$ species were removed by the addition of NaSH to allow NMR spectra to be acquired

would give a stream containing the same reactants although a far higher concentration of reagents could, in principle, be achieved. Alternatively, there could be a convergence of three streams, one of each containing glycolonitrile $4, \mathrm{NaHSO}_{3}$ and $\mathrm{NaH}_{2} \mathrm{PO}_{4} / \mathrm{K}_{4}[\mathrm{Fe}$ $\left.(\mathrm{CN})_{6}\right]$, respectively. While contemplating these possibilities, a most pertinent point presented itself; if various streams were converging delivering reagents and substrates, after each interface the concentration of all solutes would be decreased. By how much would depend on the volume and flow rate of each stream, and, accordingly, may or may not still allow productive chemistry to occur. The number of permutations for the possible reaction sequences and reaction parameters was becoming excessive to investigate, but it was apparent that a means of concentration would lend credence to our geochemical scenario.

Prebiotic protection and concentration of aldehydes. In view of this, our focus shifted to the glycolaldehyde-bisulfite adduct 7, which was always formed, to some extent, in our reactions. If the reduced glycolonitrile 4 could be trapped as 7 , ideally in one pot, there was a chance that we could concentrate the sulfonate product. Indeed, the ability of bisulfite to trap aldehydes in a prebiotic setting has been demonstrated before by Pitsch et al., who used hydrotalcite sulfite to sequester aldehydes in the interstitial layers of the mineral ${ }^{43}$. By increasing the starting concentration of bisulfite, the reduction of glycolonitrile $\mathbf{4}$ to glycolaldehyde 5 with subsequent in situ addition of bisulfite became remarkably efficient. After $1.5 \mathrm{~h}$ irradiation of a solution of $4(30 \mathrm{mM})$ in the presence of $\mathrm{Na}_{2} \mathrm{SO}_{3}(150 \mathrm{mM}), \mathrm{NaH}_{2} \mathrm{PO}_{4}(100 \mathrm{mM})$ and $\mathrm{K}_{4}[\mathrm{Fe}$ $\left.(\mathrm{CN})_{6}\right](17 \mathrm{~mol} \%), 7$ could be formed in $\sim 80 \%$ yield (Supplementary Fig. 3), with ca. $5 \%$ of 4 remaining. Even at $\mathrm{pH} 6.5$, with phosphate acting as a general acid-base catalyst, the addition of $\mathrm{HSO}_{3}{ }^{-}$was competitive with the hydrolysis of glycolaldehyde imine 8-the first product from the reduction of glycolonitrile 4 .

We then sought to exploit the kinetic and thermodynamic preference for bisulfite adduct formation to concentrate formaldehyde 2 and glycolaldehyde 5-the two most abundant aldehydes, according to our scheme, and pertinent to prebiotic amino acid and nucleotide synthesis ${ }^{26}$. Hence, we took aqueous solutions of 2 and 5 in phosphate buffer (1 eq.) in the presence and absence of $\mathrm{HSO}_{3}{ }^{-}$(1.2 eq.) at $\mathrm{pH} 6.5$ and heated them open to the air at $55^{\circ} \mathrm{C}$ for $40 \mathrm{~h}$. The solid residues were redissolved in $\mathrm{D}_{2} \mathrm{O}$ and examined by ${ }^{1} \mathrm{H}$ NMR spectroscopy (Fig. $4 \mathrm{a}, \mathrm{b}$ ). We found $>55 \%$ of formaldehyde 2 was recovered as its bisulfite adduct 9, hydroxymethanesulfonate (HMSA), after the evaporation process but, not unexpectedly, in the absence of bisulfite $\mathbf{2}$ evaporated completely (Fig. 4a). In the case of glycolaldehyde 5, $>90 \%$ of the aldehyde was recovered as its bisulfite adduct 7 or as its hydrate-presumably a small amount of bisulfite was lost in the drying process in the form of $\mathrm{SO}_{2}$ (Fig. 4b). In the absence of bisulfite, no glycolaldehyde 5 remained. A small amount of oligomerisation was observed (signals observed at $3.4-3.8 \mathrm{ppm}$ and 4.3-4.5 ppm, Fig. 4b, lower spectrum) and some material was lost through evaporation, but the majority of the material reacted with atmospheric $\mathrm{O}_{2}$ to give glycolate (3.85 ppm, singlet, Fig. $4 \mathrm{~b}$, lower spectrum) and formate. On Hadean/Archean Earth, in the absence of oxygen, this latter pathway would not be possible, and the majority of $\mathbf{5}$ would be expected to be lost through oligomerisation and evaporation. Thus, forming the bisulfite adduct of an aldehyde not only allows it to be concentrated but also protects the aldehyde from aldol chemistry. When evaluated in these terms, we were keen to examine the ability of bisulfite to protect glyceraldehyde $\mathbf{1 0}$, as its propensity to isomerise to the thermodynamically favourable ketone, dihydroxyacetone 11 (DHA), is well known ${ }^{26}$ and must be avoided if ribo-aminooxazoline $\mathbf{1 2}$ is to be accessed via direct reaction with 2-aminooxazole 13 (Fig. 1). When a solution containing glyceraldehyde 10 and bisulfite was submitted to the same dehydrating conditions, we were gratified to find that almost all $\mathbf{1 0}$ was recovered as its bisulfite adduct 14 and only $4 \%$ was converted to DHA 11 . Yet in the absence of $\mathrm{HSO}_{3}{ }^{-}$, no $\mathbf{1 0}$ remained, again through reaction with atmospheric $\mathrm{O}_{2}$ and oligomerisation but mainly due to isomerisation to $\mathbf{1 1}$ (Fig. 4c, lower spectrum: singlet observed at $4.33 \mathrm{ppm}$ due to DHA 11, singlet observed at $3.85 \mathrm{ppm}$ due to glycolate and singlet observed at 3.49 due to the hydrate of $\mathbf{1 1}$. An enhanced spectrum can be found in Supplementary Fig. 4). We then investigated bisulfite's protective capacity a little further. Glyceraldehyde $10(100 \mathrm{mM}), \mathrm{Na}_{2} \mathrm{SO}_{3}(140 \mathrm{mM})$ and $\mathrm{NaH}_{2} \mathrm{PO}_{4}$ ( $100 \mathrm{mM}$ ) were dissolved in $\mathrm{H}_{2} \mathrm{O}$ and the solution was adjusted to $\mathrm{pH}$ 6.5. The tube was sealed and heated at $55^{\circ} \mathrm{C}$ for 14 days, after which the solution was examined by ${ }^{1} \mathrm{H}$ NMR spectroscopy. We observed that $\sim 72 \%$ of the glyceraldehyde-bisulfite adduct 14 remained intact with ca. 9\% DHA 11 and 19\% methylglyoxalbisulfite adduct 15 also present (Supplementary Fig. 5). Methylglyoxal results from the elimination of water from the enediol of the trioses $\mathbf{1 0}$ and $\mathbf{1 1}$. If glyceraldehyde $\mathbf{1 0}$ was heated under the same conditions without the inclusion of $\mathrm{HSO}_{3}{ }^{-}$for $18 \mathrm{~h}, 11$ was formed in high yield with no $\mathbf{1 0}$ remaining (Supplementary Fig. 5). Interestingly, when DHA-bisulfite adduct $\mathbf{1 6}$ was heated under the same conditions $\sim 50 \%$ of $\mathbf{1 5}$ had formed after only 24 $\mathrm{h}$, and after 14 days virtually no 16 remained but a large amount of 15 was present (Supplementary Fig. 6).

Finally, we examined the behaviour of glycolaldehyde 5 in the presence of ammonia with and without added bisulfite at high $\mathrm{pH}$ (9.2). In the absence of $\mathrm{HSO}_{3}{ }^{-}$, a trace of decomposition is evident even after $10 \mathrm{~min}$, and after 7 days little starting material remains (Fig. 5a). Once again, however, the reaction containing bisulfite exhibited excellent stability under the reaction conditions and after a week only a trace of degraded material was observed (Fig. 5b). At this juncture, it is appropriate to note that the majority of aldehydes formed in our scheme ${ }^{26}$ progress to become amino acids via Strecker synthesis (addition of $\mathrm{NH}_{4} \mathrm{CN}$ to the carbonyl). At first glance, it might appear that the formation of the aminoalkylsulfonates, from the corresponding aldehyde or aldehyde-bisulfite adduct, would thwart the synthesis of amino acids, yet the Knoevenagel-Bucherer modification of the Strecker synthesis ${ }^{44}$, proceeding precisely by these intermediates, has been known for over a century. Thus, addition of $\mathrm{KCN}$ (solution then re-adjusted to $\mathrm{pH} 9.2$ ) to the glycolaldehydeammonia-bisulfite adduct, 1-amino-2-hydroxyethylsulfonate 17, gave smooth conversion to serine aminonitrile within $2 \mathrm{~h}$ (Fig. 5b). 
a
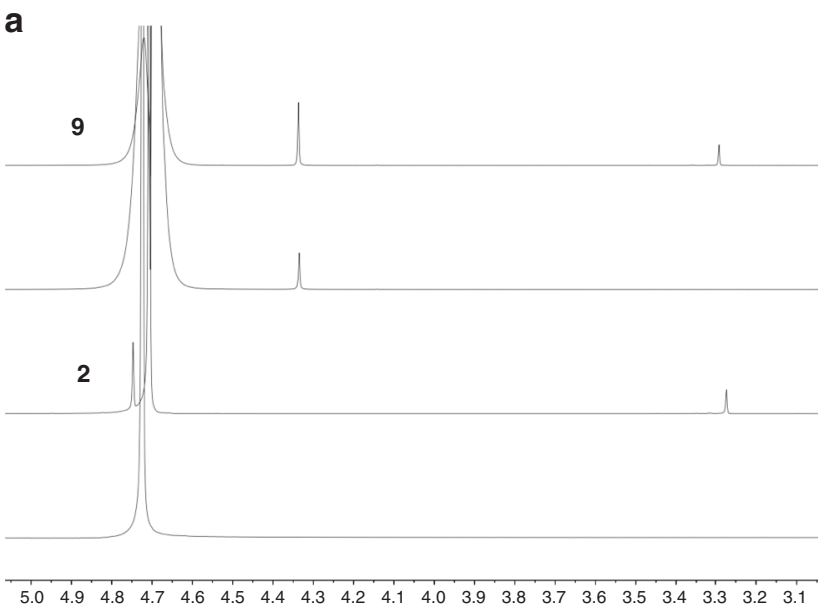

$\delta / \mathrm{ppm}$ b

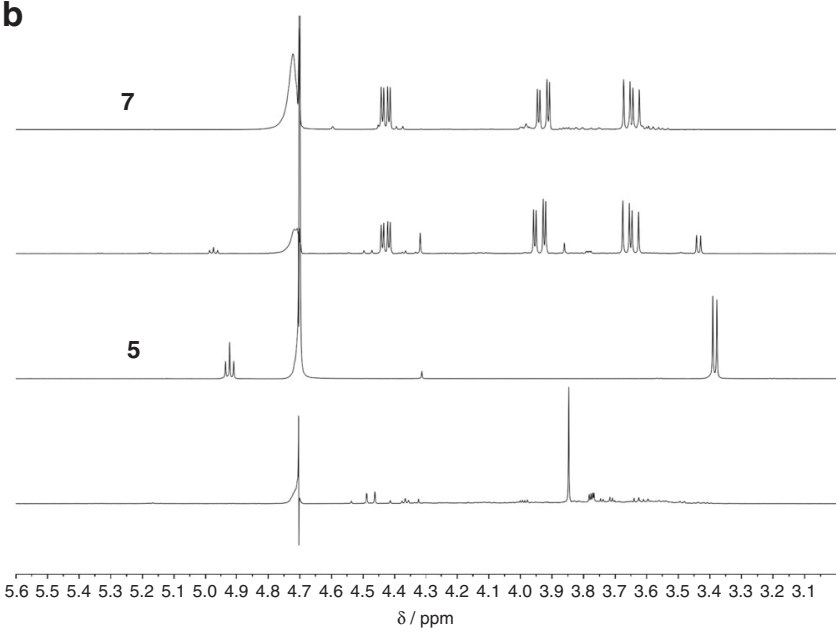

C

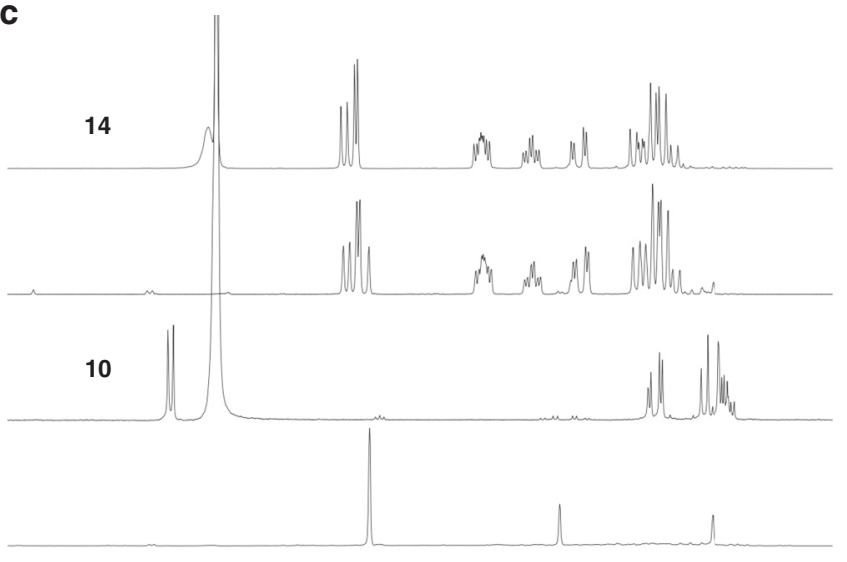

$\begin{array}{lllllllllllllllllllllllllll}5.2 & 5.1 & 5.0 & 4.9 & 4.8 & 4.7 & 4.6 & 4.5 & 4.4 & 4 & 4 & 4 & 4 & 4 & 4 & 3.9 & 3 & 3 & 3.7 & 3.6 & 3.5 & 3.4 & 3.3 & 3.2\end{array}$ $\delta / \mathrm{ppm}$

Fig. 4 Protection and concentration of aldehydes. ${ }^{1} \mathrm{H}$ NMR Spectra showing how aldehydes can be protected and concentrated under prebiotically plausible conditions via the intermediacy of their bisulfite adducts. $\mathbf{a}$ aldehyde $=$ formaldehyde $\mathbf{2}$; $\mathbf{b}$ aldehyde $=$ glycolaldehyde $\mathbf{5}$; $\mathbf{c}$ aldehyde $=$ glyceraldehyde $\mathbf{1 0}$. Upper spectra-solution of aldehyde, $\mathrm{NaH}_{2} \mathrm{PO}_{4}$ and $\mathrm{HSO}_{3}{ }^{-}$; centre upper spectra-as upper spectra after heating to dryness for $40 \mathrm{~h}$ then redissolving in $\mathrm{D}_{2} \mathrm{O}$; centre lower spectra-as upper spectra without the addition of $\mathrm{HSO}_{3}{ }^{-}$; lower spectra-as centre lower spectra after heating to dryness for $40 \mathrm{~h}$ then redissolving in $\mathrm{D}_{2} \mathrm{O}$ (in $\mathbf{a}$, the singlet observed at $3.3 \mathrm{ppm}$, upper and centre lower spectra, is $\mathrm{MeOH}$, included in commercial formaldehyde as a stabiliser)

a

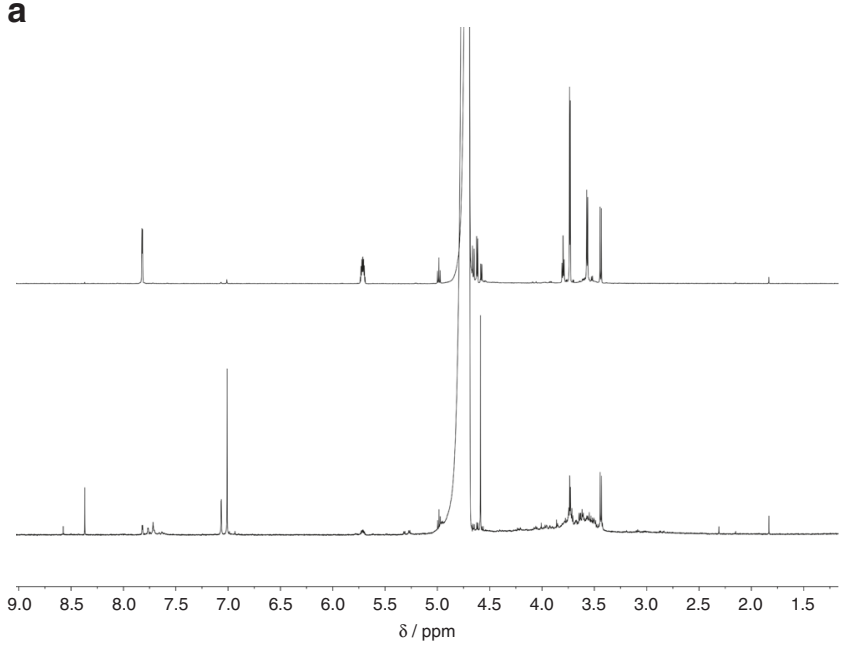

b

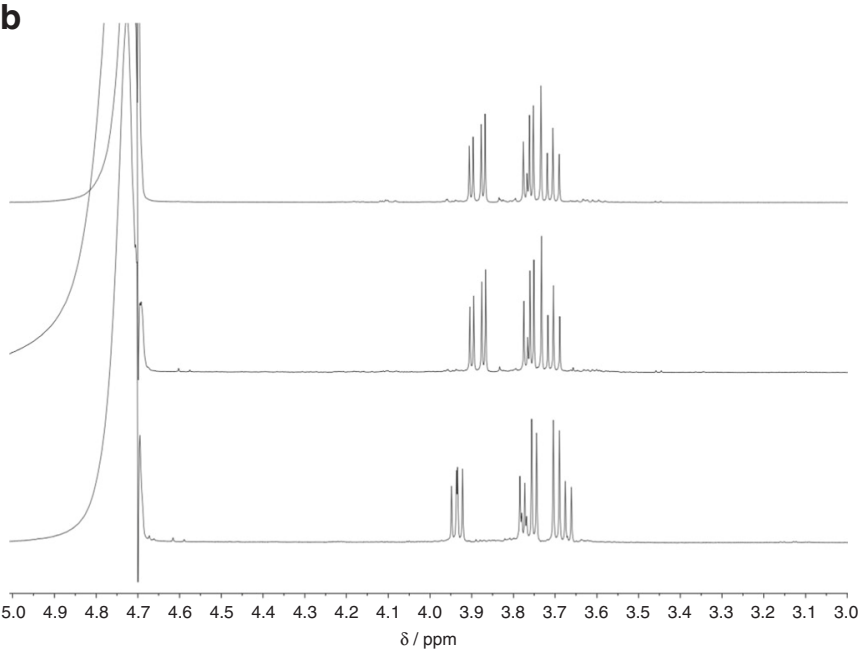

Fig. 5 Protection of $\mathbf{5}$ at high pH and modified Strecker synthesis. ${ }^{1} \mathrm{H}$ NMR Spectra showing the protection of glycolaldehyde $\mathbf{5}$ by bisulfite in the presence of $\mathrm{NH}_{3}$ and the Knoevenagel-Bucherer modified Strecker synthesis of serine aminonitrile. a Upper spectrum- $\mathbf{5}$ in $\mathrm{H}_{2} \mathrm{O} / \mathrm{D}_{2} \mathrm{O}$ with $\mathrm{NH}_{3}$ at pH 9.2 after 10 min; lower spectrum - as upper spectrum after 7 days at room temperature. b Upper spectrum- $\mathbf{5}$ and $\mathrm{Na}_{2} \mathrm{SO}_{3}$ in $\mathrm{H}_{2} \mathrm{O} / \mathrm{D}_{2} \mathrm{O}$ with $\mathrm{NH}_{3}$ at pH 9.2 after 10 min; centre spectrum-as upper spectrum after 7 days; lower-as centre spectrum with $\mathrm{KCN}$ added after $2 \mathrm{~h}, \mathrm{pH} 9.2$ 


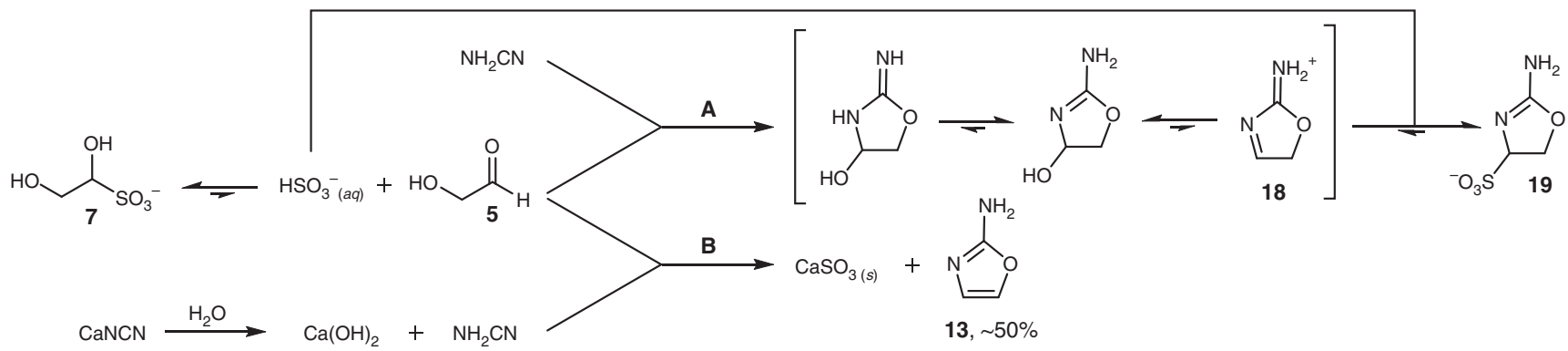

Fig. 6 Reactions of $\mathbf{7}$ with $\mathrm{NH}_{2} \mathrm{CN}$ and $\mathrm{CaNCN}$. The use of cyanamide, when attempting to form 2-AO $\mathbf{1 3}$ from $\mathbf{7}$ (pathway A), results in the undesirable reaction of displaced bisulfite with $\mathbf{1 8}$, but using calcium cyanamide circumvents this problem by precipitating calcium sulfite (pathway B)

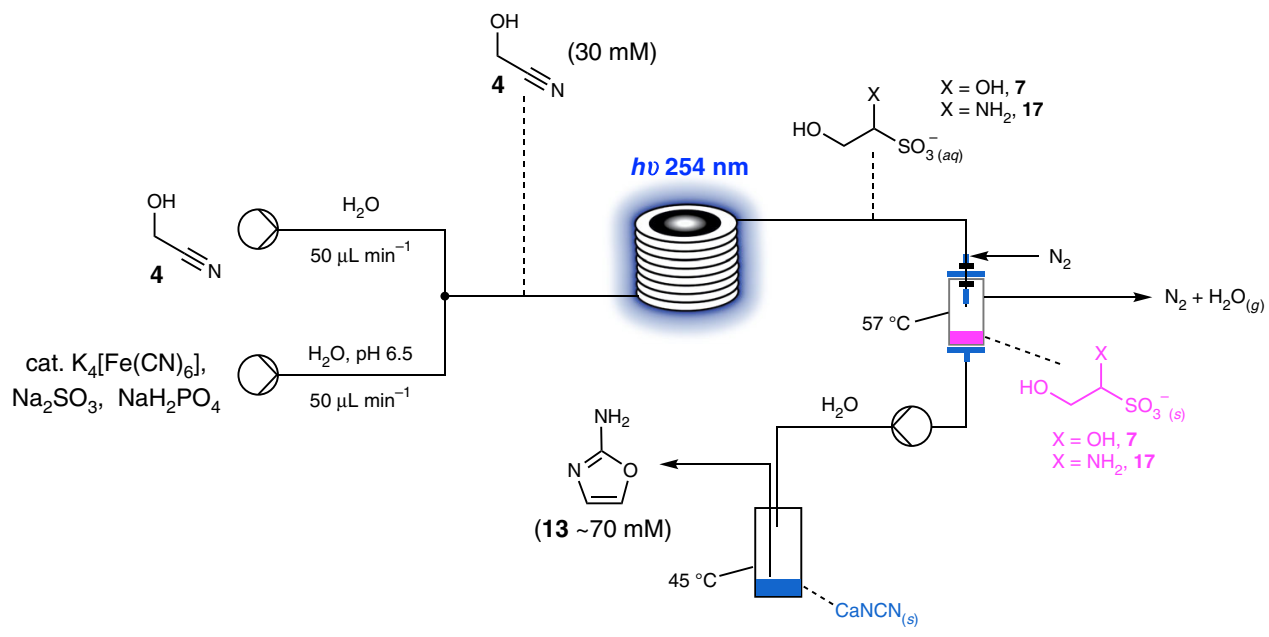

Fig. 7 Flow chemistry set-up starting with glycolonitrile 4. This arrangement was designed to simulate a possible geochemical environment on early Earth (see main text). Initial concentrations: glycolonitrile 4 (60 mM), Na $\mathrm{SO}_{3}(200 \mathrm{mM}), \mathrm{NaH}_{2} \mathrm{PO}_{4}(50 \mathrm{mM})$ and $\mathrm{K}_{4}\left[\mathrm{Fe}(\mathrm{CN})_{6}\right](10 \mathrm{mM})$

In keeping with the modified scenario, 2-aminooxazole 13 would now have to be made from the bisulfite adduct of glycolaldehyde 7 . When attempting the addition of cyanamide to 7, two problems became apparent. First, the favourable kinetics and thermodynamics for the formation of the aldehyde's bisulfite adduct coupled with cyanamide's moderate nucleophilicity meant that the rate of addition of cyanamide to glycolaldehyde $\mathbf{5}$ was markedly hindered. Second, $\mathrm{HSO}_{3}{ }^{-}$that was slowly displaced from glycolaldehyde-bisulfite adduct 7 , allowing cyanamide to react, then returned to displace hydroxide (presumably dissociatively via iminium 18) and give aminooxazoline 19 quantitatively (Fig. 6, pathway A and Supplementary Fig. 7). Although there were several potential strategies which could be employed to circumvent this problem, the most succinct solution arose from considering the geochemical scenario we had proposed. Therein, cyanamide is derived from the thermal metamorphosis of $\mathrm{Ca}_{2}[\mathrm{Fe}$ $\left.(\mathrm{CN})_{6}\right]$ (Fig. 2), the product being calcium cyanamide, $\mathrm{CaNCN}^{45}$. It transpires, most fortuitously, that calcium bisulfite is highly insoluble in $\mathrm{H}_{2} \mathrm{O}$. Also, calcium cyanamide is immediately hydrolysed to $\mathrm{Ca}(\mathrm{OH})_{2}$ and $\mathrm{NH}_{2} \mathrm{CN}$ upon contact with water, so if a stream of glycolaldehyde-bisulfite adduct 7 ran over a deposit of $\mathrm{CaNCN}$, or encountered another stream which had done so, the small amount of bisulfite present at equilibrium should precipitate as $\mathrm{CaSO}_{3}$ leaving free glycolaldehyde $\mathbf{5}$ and cyanamide in solution (Fig. 6, pathway B). Indeed, when $\mathrm{CaNCN}$ (3.5 eq.) was added to $7(50 \mathrm{mM})$ and $\mathrm{NaH}_{2} \mathrm{PO}_{4}(50 \mathrm{mM})$ at $\mathrm{pH}$ 6.5 and heated to $45^{\circ} \mathrm{C}$ for $12 \mathrm{~h}, 2$-aminooxazole 13 was formed in $\sim 50 \%$ yield (Supplementary Fig. 7 ).
Uninterrupted flow synthesis of 2-aminooxazole 13. With the individual steps to 2-aminooxazole 13 now demonstrated, we set about stringing together an uninterrupted sequence to mimic a plausible environment on early Earth using flow chemistry equipment. Thus, a solution of glycolonitrile 4 was merged with a stream containing $\mathrm{NaHSO}_{3}, \mathrm{~K}_{4}\left[\mathrm{Fe}(\mathrm{CN})_{6}\right]$ and $\mathrm{NaH}_{2} \mathrm{PO}_{4}$ and pumped through a photochemical flow reactor, fitted with an $\mathrm{Hg}$ lamp, and an optimisation regime began (Fig. 7). Once conditions for the first step were resolved, we connected the outlet of the photochemical reactor to a solvent-switch system ${ }^{46}$ heated to $57^{\circ}$ $\mathrm{C}$ and with sufficient $\mathrm{N}_{2}$ pressure to remove $\mathrm{H}_{2} \mathrm{O}$ to the point of dryness (Fig. 7). After $100 \mathrm{~min}$, the input stream was stopped and a small amount of $\mathrm{H}_{2} \mathrm{O}$ (typically $0.5-1.0 \mathrm{~mL}$ ) was pumped into the collection chamber. The resulting solution was then pumped into a small vessel containing CaNCN heated at $45^{\circ}$ C for $3-6 \mathrm{~h}$, after which time, the reaction was allowed to cool and sediment for several hours. An aliquot of the resulting clear, yellow/brown solution was then diluted in $\mathrm{D}_{2} \mathrm{O}$ and examined by ${ }^{1} \mathrm{H}$ NMR spectroscopy. We were pleased to find 2-aminooxazole 13 had been formed in a very clean reaction with only one other major by-product (Supplementary Fig. 9). Furthermore, the concentration of 13 was now of the order of $\sim 70 \mathrm{mM} c f .30 \mathrm{mM}$ glycolonitrile 4 before the photochemical reduction.

With the intrinsic stability and involatility of hydroxyalkylsulfonates demonstrably apparent, we wondered if we could lower the concentration of glycolonitrile 4 and still obtain significant concentrations of 2-aminooxazole 13. In a one-off, unoptimised experiment, we reduced the initial concentration of 


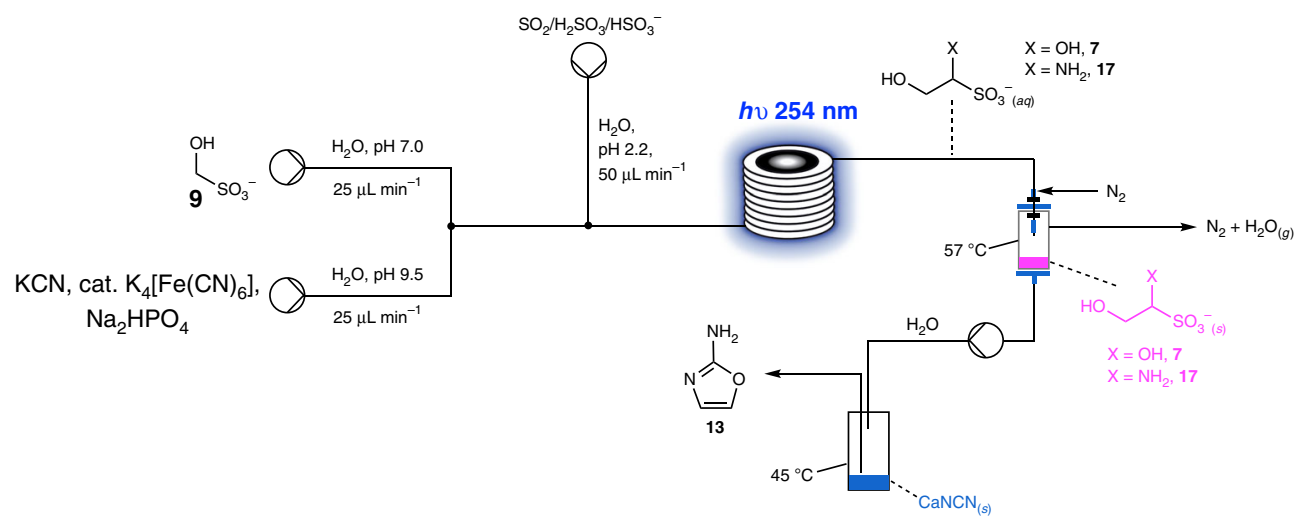

Fig. 8 Flow chemistry set-up starting with HMSA 9. This arrangement was designed to mimic the second variant of our geochemical scenario (see main text)

4 to $4 \mathrm{mM}$ (and other reagents in accordance), giving a solution of $2 \mathrm{mM}$ in 4 before UV irradiation. Following the procedure as before, we obtained a final solution with concentration of 13 in the order of $\sim 35 \mathrm{mM}$. Such a powerful mechanism for obtaining reasonably concentrated solutions of prebiologically relevant compounds warranted further investigation. Therefore (under batch conditions) we lowered the concentration of glycolonitrile 4 to $500 \mu \mathrm{M}$ (approaching the limit of satisfactory ${ }^{1} \mathrm{H}$ NMR spectroscopy) and irradiated the sample at $254 \mathrm{~nm}$ in the presence of $\mathrm{NaHSO}_{3}(2.3 \mathrm{mM}), \mathrm{NaH}_{2} \mathrm{PO}_{4}(1 \mathrm{mM})$ and $\mathrm{K}_{4}[\mathrm{Fe}$ $\left.(\mathrm{CN})_{6}\right](100 \mu \mathrm{M})$. At such low concentrations we anticipated a severe retardation in the rate of reduction, but counterintuitively, the reaction was almost complete after $20 \mathrm{~min}$ (Supplementary Fig. 10). Evidently, the reductant, $\mathrm{H}^{\bullet}$ and/or $\mathrm{e}^{-}{ }_{(a q)}$, was diffusing very rapidly through $\mathrm{H}_{2} \mathrm{O}$, possibly via a Grotthuss-like mechanism in the case of the former or hopping solvent cages in the case of the latter. This suggested, at higher concentrations, the rate of reduction was not the limiting factor but the supply of the reductant. If $\mathrm{HSO}_{3}{ }^{-}$was acting as a filter for UV light, at higher concentrations $\mathrm{Fe}(\mathrm{CN})_{6}{ }^{4-}$ would be competing with sulfur for photons/unit volume, but at low concentration, photons were now, presumably, in excess. In view of these findings, we then examined the same reaction in the absence of ferrocyanide; as $\mathrm{HSO}_{3}{ }^{-}$alone can function as a reasonable reducing agent under UV irradiation ${ }^{28}$. Although somewhat slower, the reduction of glycolonitrile 4 was $>50 \%$ complete after only $1 \mathrm{~h}$, and the only observable product was the bisulfite adduct 7 (Supplementary Fig. 11). Possibly the reaction could be run at lower concentrations still, which raised the possibility of atmospheric chemistry taking place in water droplets with 7 then raining onto Earth. In theory, a saturated solution of 2-aminooxazole 13 would be possible starting from very low concentrations of glycolonitrile 4 , but the fact that carbon is produced in the synthesis of $\mathrm{CaNCN}$ coupled with the fact that $\mathrm{CaSO}_{3}$ is insoluble means that this is not the case. The suspension that forms upon reaction must sediment, and above a certain concentration this appears unlikely to occur under our laboratory conditions. From the current studies, we would put an upper limit of $\sim 150 \mathrm{mM}$ for solutions of 2-aminooxazole 13 formed via the described chemistry.

If $\mathrm{SO}_{2}$ was abundant, it follows that HMSA 9 would have accumulated on Earth, and consequently, we wondered if there was a way we could tap into what should have been a plentiful source of a $\mathrm{C}_{1}$-feedstock molecule. At neutral $\mathrm{pH}$ in the presence of an equimolar concentration of $\mathrm{HCN} \mathrm{3,} \mathrm{equilibrium} \mathrm{lies} \mathrm{in}$ favour of glycolonitrile $\mathbf{4}$ over $\mathbf{9}$. However, exchange is extremely sluggish, and even after 1 week equilibrium is not reached (Supplementary Fig. 12). Once again, we considered the reagents available to us defined by our geochemical model and considered a stream containing HMSA 9 moving over an area where K/ $\mathrm{NaCN}$ had been deposited (Fig. 2). At high $\mathrm{pH}$, the exchange of $\mathrm{NC}^{-}$and $\mathrm{HSO}_{3}{ }^{-}$is much faster, and equilibrium is attained within $15 \mathrm{~min}$ at $\mathrm{pH} 9.2$ (3:1, glycolonitrile:HMSA, Supplementary Fig. 13). If $\mathrm{SO}_{2} / \mathrm{SO}_{2} \cdot \mathrm{xH}_{2} \mathrm{O} / \mathrm{HSO}_{3}{ }^{-}$was rained into the alkaline stream of glycolonitrile 4 , the $\mathrm{pH}$ could be dropped instantly. We attempted to recreate this situation with the flow chemistry apparatus by merging three streams: one containing HMSA 9 at $\mathrm{pH} 7.0$, one containing $\mathrm{KCN}, \mathrm{Na}_{2} \mathrm{HPO}_{4}$ and $\mathrm{K}[\mathrm{Fe}$ $\left.(\mathrm{CN})_{6}\right]$ at $\mathrm{pH} 9.5$ and one containing $\mathrm{NaHSO}_{3}$ at $\mathrm{pH} 2.2$ (Fig. 8, although the $\mathrm{p} K_{\mathrm{a}}$ of sulfurous acid is $\sim 1.8$ there would have been some buffering by $\mathrm{CO}_{2} / \mathrm{HCO}_{3(a q)}$, so we proposed a $\mathrm{pH}$ of 2.2 not to be unrealistic). The reaction was pumped through the UV reactor, concentrated and reacted with $\mathrm{CaNCN}$ as before to furnish a solution that was $>60 \mathrm{mM}$ in 2-aminooxazole $13 c f$. a theoretical maximum $30 \mathrm{mM}$ in glycolonitrile 4 after confluence of the three streams. Again, there are multiple variations of a theme which should result in the same chemical outcome. For example, atmospheric $\mathrm{CO}_{2}$ could buffer the solution of 4 formed after a stream of HMSA 9 had encountered $\mathrm{K} / \mathrm{NaCN}$, which may take a little more time but would certainly be expected. Or, a stream of 9 and HCN could have come into contact with alkaline streams/evaporite beds-resulting from the serpentinisation of ultramafic rock-which would temporarily raise the $\mathrm{pH}$ and facilitate the exchange of $\mathrm{NC}^{-}$and $\mathrm{HSO}_{3}{ }^{-}$. Once again, the number of permutations of reaction sequences, coupled with all the variable reaction parameters, was prohibitive to investigate without high throughput, multiplet flow apparatus, but we were satisfied a convincing demonstration of the uninterrupted synthesis of 2-aminooxazole 13 starting from $\mathrm{C}_{1}$-building blocks was complete.

\section{Discussion}

Pinning down a precise geochemical scenario which could lead down a predisposed trajectory towards life is understandably challenging. In the described work, we have sought to take the initial steps to a "continuous" 47 synthesis of ribonucleotides from prebiotically available $\mathrm{C}_{1}$ or $\mathrm{C}_{2}$-starting materials. During the course of the investigation, we found that bisulfite, previously used to reduce HCN 3 to glycolonitrile 4, glyceronitrile 6 and glyceraldehyde cyanohydrin ${ }^{28}$, could be used to form glycolaldehyde-bisulfite adduct 7 directly from 4 in high yield. We had been cognisant of the fact that if the $\mathrm{Cu}^{+} / \mathrm{HS}^{-}$photochemistry previously described ${ }^{26,27}$ occurred at a time when cyanide concentrations were low, the resulting aldehydes would be left in solution and degradation would be expected to take place over a period of days/weeks. However, we have found that 
a
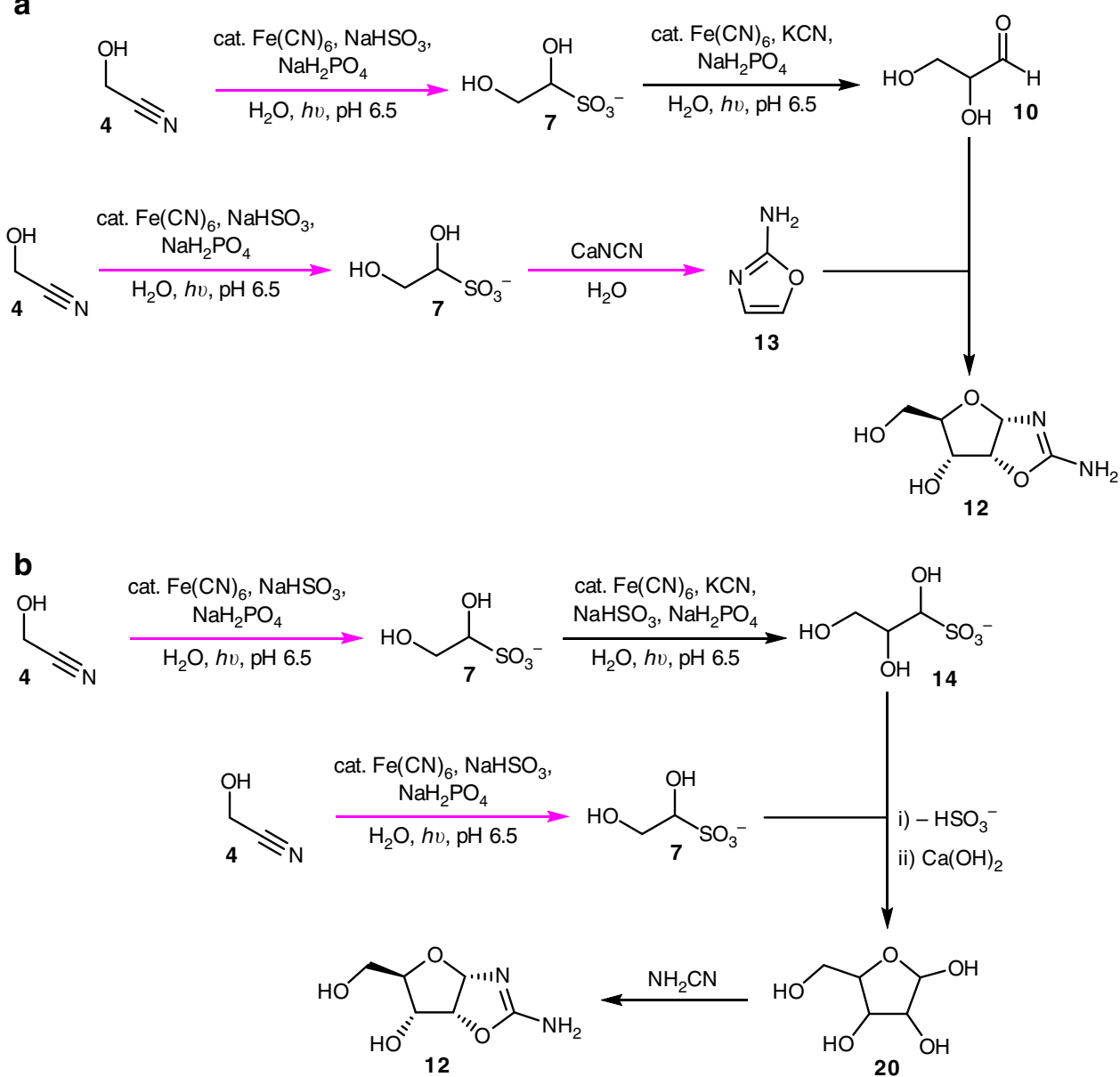

Fig. 9 The two viable routes to ribo-aminooxazoline $\mathbf{1 2}$ starting from $\mathbf{4}$. All steps have been demonstrated under batch conditions, but those steps depicted in magenta have been performed in flow conditions in a "continuous"48, uninterrupted manner starting from glycolonitrile $\mathbf{4}$ or HMSA $\mathbf{9}$. a Route to $\mathbf{1 2}$ via the addition of 2-AO $\mathbf{1 3}$ to glyceraldehyde $\mathbf{1 0}$. b Route to $\mathbf{1 2}$ via aldol reaction of $\mathbf{5}$ and $\mathbf{1 0}$ after their liberation from $\mathbf{7}$ and $\mathbf{1 4}$, respectively

bisulfite adduct formation is an extremely effective way of stabilising aldehydes, almost halting degradation pathways completely. Even in the presence of ammonia at high $\mathrm{pH}$, the aminosulfonates are incredibly robust yet, crucially, allow facile synthesis of aminonitriles in the presence of cyanide 3. Furthermore, thanks to the low $\mathrm{p} K_{\mathrm{a}}$ of the conjugate acid of the sulfonate that is formed, the bisulfite adducts can be concentrated to the point of dryness. In view of the proposed geochemical scenario, a concentration mechanism of volatile intermediates would appear to be an essential requirement, and has been realised by adopting recent suggestions concerning Earth's primitive atmosphere ${ }^{30-33}$. Finally, glycolaldehyde $\mathbf{5}$ is required for the synthesis of 2 -aminooxazole 13 , but in this case, bisulfite interferes with 2 -aminooxazole 13 synthesis. The simplest solution to this problem - removal of bisulfite from equilibria by precipitation as $\mathrm{CaSO}_{3(s)}$ became apparent by considering the reagent $(\mathrm{CaNCN})$ that our geochemical scenario suggested, rather than the reagent we normally take from the fridge $\left(\mathrm{NH}_{2} \mathrm{CN}\right)$.

Clearly, there is a long way to go from the current position to making oligonucleotides (let alone a protocell) in an uninterrupted synthetic sequence, yet the results presented here show that the first steps along that road appear to be predisposed in favour of the necessary chemical reactions and physical processes. Furthermore, the solutions to the problems we encountered thus far have been intertwined with the geological and chemical scenario we have proposed, and allow a clean, telescoped synthesis of 2-aminooxazole 13. Thus, the generalisation that "if you have a pool of chemicals and pump energy in, you don't get life, you get asphalt" appears not to be correct if one is examining the right type of reaction sequence ${ }^{48}$. As alluded to, the number of variables at each stage is manifold, and as the scheme progresses, there appear to be alternate routes to arrive at the same intermediates. For example, the next phase should be to evaluate an uninterrupted synthesis of glyceraldehyde 10, which can react with 13 en route to the seemingly critical, crystalline intermediate ribo-aminooxazoline $12^{49}$ (Fig. 9a). However, it may be possible that a mixture of the bisulfite adducts of glycolaldehyde 5 and glyceraldehyde $\mathbf{1 0}$ could be formed, concentrated and then used in a $\mathrm{Ca}(\mathrm{OH})_{2}$-mediated aldol reaction to give pentose sugars that finally undergo reaction with cyanamide to arrive at the same, key intermediate 12 (Fig. 9b). Although there are multitudinous variations, they are variations on a theme and all fall under the umbrella of the geochemical scenario outlined here and elsewhere $^{26,34}$. However, it is not the authors wish or intent to persuade the reader that all roads must have led to Rome. In fact, we caution the opposite. While there are many small, and large, variances of sequence that could have still permitted a route to life, there are far, far more that would not. For example, if in one location a stream containing HMSA 9 ran over a deposit of CaNCN before $\mathrm{K} / \mathrm{NaCN}$ was encountered, the mixture would have been converted to an insoluble polymer (Powner and Sutherland, unpublished).

There is a general consensus that the individual reactions leading to life should be robust and high yielding, or predisposed. 
However, it is unclear whether a sequence of such reactions leading to life could occur under one set of conditions, or whether changes of conditions and merger of different reaction streams etc. is required. The latter would make life less probable than the former, and the results reported herein suggest the latter. It follows that the sequence of events that led to life must have been highly contingent and the origin of life as we know it could have been a low probability event.

\section{Methods}

General procedure for $\mathbf{U V}$ irradiation experiments in batch. In $10 \% \mathrm{D}_{2} \mathrm{O} / \mathrm{H}_{2} \mathrm{O}$ (degassed), $\mathrm{NaH}_{2} \mathrm{PO}_{4} \cdot 2 \mathrm{H}_{2} \mathrm{O}$ and $\mathrm{Na}_{2} \mathrm{SO}_{3}$ were dissolved and the solution was adjusted to $\mathrm{pH} 6.5$ with degassed $\mathrm{HCl} / \mathrm{NaOH}$. The volume was made up to the desired amount using degassed $10 \% \mathrm{D}_{2} \mathrm{O} / \mathrm{H}_{2} \mathrm{O}$ and glycolonitrile 4 and $\mathrm{K}_{4}[\mathrm{Fe}$ $(\mathrm{CN})_{6}$ ] (if required) were added. The solution was transferred to a quartz cuvette, stoppered and irradiated for the desired length of time. A sample was then removed, to which $\mathrm{NaSH}_{\mathrm{xH}} \mathrm{O}$ O (typically $1-2 \mathrm{mg}$ ) was added, centrifuged and analysed by ${ }^{1} \mathrm{H}$ NMR spectroscopy.

General procedure for dry-down experiments. In an Eppendorf, the aldehyde $(0.050 \mathrm{mmol})$ was dissolved in a solution of $\mathrm{NaH}_{2} \mathrm{PO}_{4} \cdot 2 \mathrm{H}_{2} \mathrm{O}(8 \mathrm{mg}, 0.050 \mathrm{mmol})$ and $\mathrm{Na}_{2} \mathrm{SO}_{3}\left(8 \mathrm{mg}, 0.060 \mathrm{mmol}\right.$, if required) in degassed $\mathrm{H}_{2} \mathrm{O}(0.6 \mathrm{~mL})$ and the $\mathrm{pH}$ adjusted to 6.5 with degassed $\mathrm{HCl} / \mathrm{NaOH}$. The volume was made up to $1 \mathrm{~mL}$ with degassed $\mathrm{H}_{2} \mathrm{O}$ and heated to $55^{\circ} \mathrm{C}$, with stirring, open to the air for $40 \mathrm{~h}$. Although the samples were dry in under $40 \mathrm{~h}$, we wished to test the stability of the bisulfite adducts in the dry state also. The residue was dissolved in $\mathrm{D}_{2} \mathrm{O}$ and analysed by ${ }^{1} \mathrm{H}$ NMR spectroscopy.

Stability of 10, 14 and 16 in solution. In an Eppendorf, the carbonyl compound $(9 \mathrm{mg}, 0.100 \mathrm{mmol})$ was dissolved in a solution of $\mathrm{NaH}_{2} \mathrm{PO}_{4} \cdot 2 \mathrm{H}_{2} \mathrm{O}(16 \mathrm{mg}, 0.100$ mmol) and $\mathrm{Na}_{2} \mathrm{SO}_{3}\left(18 \mathrm{mg}, 0.140 \mathrm{mmol}\right.$, if required) in degassed $10 \% \mathrm{D}_{2} \mathrm{O} / \mathrm{H}_{2} \mathrm{O}$ $(0.6 \mathrm{~mL})$, and the $\mathrm{pH}$ adjusted to 6.5 with degassed $\mathrm{HCl} / \mathrm{NaOH}$. The volume was made up to $1 \mathrm{~mL}$ with degassed $10 \% \mathrm{D}_{2} \mathrm{O} / \mathrm{H}_{2} \mathrm{O}$, sealed, then heated to $55^{\circ} \mathrm{C}$ for the desired time. A sample was then removed and analysed by ${ }^{1} \mathrm{H}$ NMR spectroscopy.

Procedure for checking the stability of $\mathbf{5}$ and $\mathbf{7}$ at high $\mathbf{p H}$. In an Eppendorf, glycolaldehyde $5(3 \mathrm{mg}, 0.050 \mathrm{mmol})$ was dissolved in a solution of $\mathrm{Na}_{2} \mathrm{SO}_{3}(7 \mathrm{mg}$, $0.060 \mathrm{mmol}$, if required) in degassed $10 \% \mathrm{D}_{2} \mathrm{O} / \mathrm{H}_{2} \mathrm{O}(0.5 \mathrm{~mL})$ and c. $\mathrm{NH}_{4} \mathrm{OH}(100$ $\mu \mathrm{L}$ ) added. The $\mathrm{pH}$ was adjusted to 9.2 with degassed $\mathrm{HCl} / \mathrm{NaOH}$, the volume was made up to $1 \mathrm{~mL}$ with degassed $10 \% \mathrm{D}_{2} \mathrm{O} / \mathrm{H}_{2} \mathrm{O}$ and the reaction was sealed. ${ }^{1} \mathrm{H}$ NMR spectroscopy was performed at desired time points.

Knoevenagel-Bucherer-Strecker synthesis of serine nitrile. After 7 days, to the reaction above containing bisulfite $(500 \mu \mathrm{L})$, KCN $3(3 \mathrm{mg}, 0.050 \mathrm{mmol})$ was added. The $\mathrm{pH}$ increased to 9.3 but was readjusted to $9.2 .{ }^{1} \mathrm{H}$ NMR spectroscopy was performed at desired time points.

Reaction of 7 with $\mathbf{N H}_{2} \mathbf{C N}$ and CaNCN. Glycolaldehyde $\mathbf{5}(3 \mathrm{mg}, 0.050 \mathrm{mmol})$ was dissolved in a solution of $\mathrm{Na}_{2} \mathrm{SO}_{3}(8 \mathrm{mg}, 0.060 \mathrm{mmol})$ and $\mathrm{NaH}_{2} \mathrm{PO}_{4} \cdot 2 \mathrm{H}_{2} \mathrm{O}(8$ $\mathrm{mg}, 0.050 \mathrm{mmol})$ in degassed $10 \% \mathrm{D}_{2} \mathrm{O} / \mathrm{H}_{2} \mathrm{O}(0.6 \mathrm{~mL})$, and the $\mathrm{pH}$ was adjusted to 6.5 with degassed $\mathrm{HCl} / \mathrm{NaOH}$. The volume was made up to $1 \mathrm{~mL}$ using degassed $10 \% \mathrm{D}_{2} \mathrm{O} / \mathrm{H}_{2} \mathrm{O}$, and either cyanamide or calcium cyanamide were added $(0.175$ $\mathrm{mmol}$ ). The reaction was heated to $45^{\circ} \mathrm{C}$ for the desired time and a sample was removed and examined by ${ }^{1} \mathrm{H}$ NMR spectroscopy (in the reaction using $\mathrm{CaNCN}$, the Eppendorf was briefly centrifuged to obtain a clear solution for NMR spectroscopy. The resulting pellet was resuspended before continuing the reaction).

Reaction of 13 with bisulfite. A solution of $\mathrm{Na}_{2} \mathrm{SO}_{3}(8 \mathrm{mg}, 0.060 \mathrm{mmol})$ and $\mathrm{NaH}_{2} \mathrm{PO}_{4} \cdot 2 \mathrm{H}_{2} \mathrm{O}(8 \mathrm{mg}, 0.050 \mathrm{mmol})$ in degassed $10 \% \mathrm{D}_{2} \mathrm{O} / \mathrm{H}_{2} \mathrm{O}(1 \mathrm{~mL})$ was adjusted to $\mathrm{pH} 6.5$ and 2-aminooxazole $13(4 \mathrm{mg}, 0.050 \mathrm{mmol})$ was added. The reaction was sealed and heated overnight at $45^{\circ} \mathrm{C}$ before being analysed by ${ }^{1} \mathrm{H}$ NMR spectroscopy.

Flow chemistry procedure starting from glycolonitrile 4. In one vessel, glycolonitrile $4(55 \%, 119 \mu \mathrm{L}, 1.20 \mathrm{mmol})$ was dissolved in degassed $\mathrm{H}_{2} \mathrm{O}(20 \mathrm{~mL})$ and kept under $\mathrm{N}_{2}$ atmosphere. A second vessel was charged with degassed $\mathrm{H}_{2} \mathrm{O}(15 \mathrm{~mL})$, $\mathrm{Na}_{2} \mathrm{SO}_{3}(504 \mathrm{mg}, 4.00 \mathrm{mmol})$ and $\mathrm{NaH}_{2} \mathrm{PO}_{4}(120 \mathrm{mg}, 1.00 \mathrm{mmol})$, and the $\mathrm{pH}$ was adjusted to 6.5 with degassed $\mathrm{HCl} / \mathrm{NaOH}$. The volume was made up to $20 \mathrm{~mL}$ with degassed $\mathrm{H}_{2} \mathrm{O}$ and $\mathrm{K}_{4}\left[\mathrm{Fe}(\mathrm{CN})_{6}\right] .3 \mathrm{H}_{2} \mathrm{O}(84 \mathrm{mg}, 0.200 \mathrm{mmol})$ was added and the solution was kept under $\mathrm{N}_{2}$ atmosphere. The two solutions were pumped at a rate of $50 \mu \mathrm{L} \mathrm{min}^{-1}$ each and merged via a T-piece. The solution was then pumped through a photochemical flow reactor at $25^{\circ} \mathrm{C}$ (overall flow rate $100 \mu \mathrm{L} \mathrm{min}{ }^{-1}, 10 \mathrm{~mL}$ reactor coil (100 min total irradiation time), and a backpressure regulator was fitted at the output and adjusted so a pressure of $\sim 2$ bar was maintained) [the output was checked at the desired time points via the addition of $\mathrm{NaSH} \mathrm{XH}_{2} \mathrm{O}(1-2 \mathrm{mg})$, doping with $\mathrm{D}_{2} \mathrm{O}$ and acquiring solvent suppression ${ }^{1} \mathrm{H}$ NMR spectra]. The reactor output was then delivered to an in-line solvent-switch system ${ }^{46}$ heated at $57^{\circ} \mathrm{C}$ with an influx of $\mathrm{N}_{2}$ set at a pressure such that the output was concentrated to dryness. After $100 \mathrm{~min}$ of collection, the input was ceased, and degassed $\mathrm{H}_{2} \mathrm{O}$ (typically $0.5-1 \mathrm{~mL}$ ) was either pumped or syringed into the solvent switch. The chamber was agitated gently to facilitate dissolution of the solids, and the solution was then pumped into an Eppendorf containing CaNCN $(90 \%, 71 \mathrm{mg}, 0.797 \mathrm{mmol})$ and stirrer bar. The Eppendorf was sealed and the suspension was stirred and heated at $45^{\circ} \mathrm{C}$ for the desired time, after which the reaction was allowed to cool to room temperature and sediment for several hours. An aliquot of the clear solution was then dissolved in $\mathrm{D}_{2} \mathrm{O}$ and examined by ${ }^{1} \mathrm{H}$ NMR spectroscopy.

Flow chemistry procedure starting from HMSA 9. In one vessel, $\mathrm{Na}_{2} \mathrm{SO}_{3}(302$ $\mathrm{mg}, 2.40 \mathrm{mmol})$ and formaldehyde $(37 \%, 180 \mu \mathrm{L}, 2.40 \mathrm{mmol})$ were dissolved in degassed $\mathrm{H}_{2} \mathrm{O}(15 \mathrm{~mL})$, and the $\mathrm{pH}$ adjusted to 7.0 with degassed $\mathrm{HCl} / \mathrm{NaOH}$. The volume was made up to $20 \mathrm{~mL}$ with degassed $\mathrm{H}_{2} \mathrm{O}$ and kept under $\mathrm{N}_{2}$ atmosphere (solution A). In a second vessel, $\mathrm{KCN}(182 \mathrm{mg}, 2.80 \mathrm{mmol}), \mathrm{NaH}_{2} \mathrm{PO}_{4}(240 \mathrm{mg}$, $2.00 \mathrm{mmol})$ and $\mathrm{K}_{4}\left[\mathrm{Fe}(\mathrm{CN})_{6}\right] .3 \mathrm{H}_{2} \mathrm{O}(167 \mathrm{mg}, 0.400 \mathrm{mmol})$ were dissolved in degassed $\mathrm{H}_{2} \mathrm{O}(15 \mathrm{~mL})$ and the $\mathrm{pH}$ adjusted to 9.5 with degassed $\mathrm{HCl} / \mathrm{NaOH}$. The volume was made up to $20 \mathrm{~mL}$ with degassed $\mathrm{H}_{2} \mathrm{O}$ and kept under $\mathrm{N}_{2}$ atmosphere (solution B). A third vessel was charged with $\mathrm{Na}_{2} \mathrm{SO}_{3}(328 \mathrm{mg}, 2.60 \mathrm{mmol}$ ) and degassed $\mathrm{H}_{2} \mathrm{O}(15 \mathrm{~mL})$, and the $\mathrm{pH}$ adjusted to 2.2 with degassed $\mathrm{HCl} / \mathrm{NaOH}$. The volume was made up to $20 \mathrm{~mL}$ with degassed $\mathrm{H}_{2} \mathrm{O}$ and kept under $\mathrm{N}_{2}$ atmosphere (solution C). Solutions A and B were pumped at a rate of $25 \mu \mathrm{Lmin}^{-1}$ each and merged via a T-piece. The resulting reaction stream was then merged via another $\mathrm{T}$ piece with solution $C$, pumped at $50 \mu \mathrm{L} \mathrm{min}^{-1}$, and passed through the photochemical reactor at $25^{\circ} \mathrm{C}$ (overall flow rate $100 \mu \mathrm{L} \mathrm{min}^{-1}, 10 \mathrm{~mL}$ reactor coil (100 min total irradiation time), and a backpressure regulator was fitted at the output and adjusted so a pressure of $\sim 2$ bar was maintained) [the output was checked at the desired time points via the addition of $\mathrm{NaSH}_{\mathrm{XH}} \mathrm{O}(1-2 \mathrm{mg})$, doping with $\mathrm{D}_{2} \mathrm{O}$ and acquiring solvent suppression ${ }^{1} \mathrm{H}$ NMR spectra]. The solution was then pumped into an in-line solvent-switch system ${ }^{46}$ heated at $57^{\circ} \mathrm{C}$ with an influx of $\mathrm{N}_{2}$ set at a pressure such that the output was concentrated to dryness. After $100 \mathrm{~min}$ of collection, the input was ceased and degassed $\mathrm{H}_{2} \mathrm{O}$ (typically $0.5-1 \mathrm{~mL}$ ) was either pumped or syringed into the solvent switch. The chamber was agitated gently to facilitate dissolution of the solids, and the solution was then pumped into an Eppendorf containing CaNCN $(90 \%, 71 \mathrm{mg}, 0.797 \mathrm{mmol})$ and a stirrer bar. The Eppendorf was sealed and the suspension was stirred and heated at $45^{\circ} \mathrm{C}$ for the desired time, after which the reaction was allowed to cool to room temperature and sediment for several hours. An aliquot of the clear solution was then dissolved in $\mathrm{D}_{2} \mathrm{O}$ and examined by ${ }^{1} \mathrm{H}$ NMR spectroscopy.

Equilibration of $\mathbf{K C N}, \mathbf{H S O}_{3}{ }^{-}$and $\mathbf{2}$ at neutral $\mathbf{p H}$. A solution of $\mathrm{Na}_{2} \mathrm{SO}_{3}(6.3 \mathrm{mg}$ $0.060 \mathrm{mmol}), \mathrm{NaH}_{2} \mathrm{PO}_{4} .2 \mathrm{H}_{2} \mathrm{O}(8 \mathrm{mg}, 0.050 \mathrm{mmol})$ and formaldehyde $2(37 \%, 3.8$ $\mu \mathrm{L}, 0.050 \mathrm{mmol})$ in degassed $10 \% \mathrm{D}_{2} \mathrm{O} / \mathrm{H}_{2} \mathrm{O}(0.4 \mathrm{~mL})$ was adjusted to $\mathrm{pH} 6.5$ with degassed $\mathrm{HCl} / \mathrm{NaOH}$. The volume was made up to $0.5 \mathrm{~mL}$ with degassed $10 \% \mathrm{D}_{2} \mathrm{O} /$ $\mathrm{H}_{2} \mathrm{O}$. KCN (3.3 mg, $0.050 \mathrm{mmol}$ ) was dissolved in degassed $10 \% \mathrm{D}_{2} \mathrm{O} / \mathrm{H}_{2} \mathrm{O}(0.4$ $\mathrm{mL}$ ) and adjusted to $\mathrm{pH} \sim 7$ with degassed $\mathrm{HCl} / \mathrm{NaOH}$. The volume was made up to $0.5 \mathrm{~mL}$ with degassed $10 \% \mathrm{D}_{2} \mathrm{O} / \mathrm{H}_{2} \mathrm{O}$. The two solutions were then mixed, sealed and monitored by ${ }^{1} \mathrm{H}$ NMR spectroscopy.

Equilibration of $\mathbf{K C N}, \mathbf{H S O}_{3}{ }^{-}$and $\mathbf{2}$ at high $\mathbf{p H}$. A solution of $\mathrm{Na}_{2} \mathrm{SO}_{3}(6.3 \mathrm{mg}$ $0.060 \mathrm{mmol}), \mathrm{NaH}_{2} \mathrm{PO}_{4} .2 \mathrm{H}_{2} \mathrm{O}(8 \mathrm{mg}, 0.050 \mathrm{mmol})$ and formaldehyde $2(37 \%, 3.8$ $\mu \mathrm{L}, 0.050 \mathrm{mmol})$ in degassed $10 \% \mathrm{D}_{2} \mathrm{O} / \mathrm{H}_{2} \mathrm{O}(0.4 \mathrm{~mL})$ was adjusted to $\mathrm{pH} 9.2$ with degassed $\mathrm{HCl} / \mathrm{NaOH}$. The volume was made up to $0.5 \mathrm{~mL}$ with degassed $10 \% \mathrm{D}_{2} \mathrm{O} /$ $\mathrm{H}_{2} \mathrm{O}$. KCN (3.3 mg, $\left.0.050 \mathrm{mmol}\right)$ was dissolved in degassed $10 \% \mathrm{D}_{2} \mathrm{O} / \mathrm{H}_{2} \mathrm{O}(0.4$ $\mathrm{mL}$ ) and adjusted to $\mathrm{pH} 9.2$ with degassed $\mathrm{HCl} / \mathrm{NaOH}$. The volume was made up to $0.5 \mathrm{~mL}$ with degassed $10 \% \mathrm{D}_{2} \mathrm{O} / \mathrm{H}_{2} \mathrm{O}$. The two solutions were then mixed, sealed and monitored by ${ }^{1} \mathrm{H}$ NMR spectroscopy.

Data availability. The authors declare that all data supporting the findings of this study are available within the paper and its Supplementary Information files or are available from the authors upon reasonable request.

Received: 12 January 2018 Accepted: 6 April 2018

Published online: 08 May 2018

\section{References}

1. Pace, N. R. Origin of life-facing up to the physical setting. Cell 65, 531-533 (1991)

2. Baross, J. A. \& Hoffman, S. E. Submarine hydrothermal vents and associated gradient environments as sites for the origin and evolution of life. Orig. Life Evol. Biospheres 15, 327-345 (1985).

3. Russell, M. J., Hall, A. J., Cairns-Smith, A. G. \& Braterman, P. S. Submarine hot springs and the origin of life. Nature 336, 117 (1988). 
4. Russell, M. J., Hall, A. J. \& Turner, D. In vitro growth of iron sulphide chimneys: possible culture chambers for origin-of-life experiments. Terra Nova 1, 238-241 (1989).

5. Holm, N. G. Why are hydrothermal systems proposed as plausible environments for the origin of life? Orig. Life Evol. Biospheres 22, 5-14 (1992).

6. Shock, E. L. \& Schulte, M. D. Organic synthesis during fluid mixing in hydrothermal systems. J. Geophys. Res. 103, 28513-28527 (1998).

7. Ozawa, K. et al. Phosphorylation of nucleotide molecules in hydrothermal environments. Orig. Life Evol. Biospheres 34, 465-471 (2004).

8. Russell, M. J., Daniel, R. M., Hall, A. J. \& Sherringham, J. A. A hydrothermally precipitated catalytic iron sulphide membrane as a first step toward life. J. Mol. Evol. 39, 231-243 (1994).

9. Russell, M. J. \& Hall, A. J. The emergence of life from iron monosulphide bubbles at a submarine hydrothermal redox and $\mathrm{pH}$ front. J. Geol. Soc. 154, 377-402 (1997).

10. Russell, M. J. \& Martin, W. The rocky roots of the acetyl-CoA pathway. Trends Biochem. Sci. 29, 358-363 (2004).

11. Martin, W. \& Russell, M. J. On the origin of biochemistry at an alkaline hydrothermal vent. Philos. Trans. R. Soc. B 362, 1887-1925 (2007).

12. Lane, N. Chance or necessity? Bioenergetics and the probability of life. J. Cosmol. 10, 3286-3304 (2010).

13. Russell, M. J., Nitschke, W. \& Branscomb, E. The inevitable journey to being. Philos. Trans. R. Soc. B 368, 20120254 (2013).

14. Nitschke, W. \& Russell, M. J. Beating the acetyl coenzyme A-pathway to the origin of life. Philos. Trans. R. Soc. B 368, 20120258 (2013).

15. Sojo, V., Pomiankowski, A. \& Lane, N. A bioenergetic basis for membrane divergence in Archaea and Bacteria. PLOS Biol. 12, 1-12 (2014).

16. Russell, M. J. et al. The drive to life on wet and icy worlds. Astrobiology 14, 308-343 (2014).

17. Huber, C. \& Wächtershäuser, G. Activated acetic acid by carbon fixation on (Fe,Ni)S under primordial conditions. Science 276, 245-247 (1997).

18. Butlerow, A. Bildung einer zuckerartigen substanz synthese. Liebigs Ann. Chem. 120, 295-298 (1861).

19. Palm, C. \& Calvin, M. Primordial organic chemistry. I. Compounds resulting from electron irradiation of $\mathrm{C}^{14} \mathrm{H}_{4}$. J. Am. Chem. Soc. 84, 2115-2121 (1962).

20. Shapiro, R. Prebiotic ribose synthesis: a critical analysis. Orig. Life Evol. Biospheres 18, 71-85 (1988).

21. Eschenmoser, A. \& Loewenthal, E. Chemistry of potentially prebiological natural products. Chem. Soc. Rev. 21, 1-16 (1992).

22. Vázquez-Mayagoitia, Á. et al. On the stabilization of ribose by silicate minerals. Astrobiology 11, 115-121 (2011).

23. Kim, H.-J. et al. Synthesis of carbohydrates in mineral-guided prebiotic cycles. J. Am. Chem. Soc. 133, 9457-9468 (2011).

24. Hazen, R. M. Paleomineralogy of the Hadean eon: a preliminary species list. Am. J. Sci. 313, 807-843 (2013).

25. Powner, M. W. \& Sutherland, J. D. Prebiotic chemistry: a new modus operandi. Philos. Trans. Soc. B 366, 2870-2877 (2011).

26. Patel, B. H., Percivalle, C., Ritson, D. J., Duffy, C. D. \& Sutherland, J. D. Common origins of RNA, protein and lipid precursors in a cyanosulfidic protometabolism. Nat. Chem. 7, 301-307 (2015).

27. Ritson, D. J. \& Sutherland, J. D. Synthesis of aldehydic ribonucleotide and amino acid precursors by photoredox chemistry. Angew. Chem. Int. Ed. 52, 5845-5847 (2013).

28. $\mathrm{Xu}, \mathrm{J}$. et al. Photochemical reductive homologation of hydrogen cyanide using sulfite and ferrocyanide. Chem. Commun.Accepted. 2018.

29. Trail, D., Watson, E. B. \& Tailby, N. D. The oxidation state of Hadean magmas and implications for early Earth's atmosphere. Nature 480, 79-82 (2011).

30. Kaltenegger, L. \& Sasselov, D. Detecting planetary geochemical cycles on exoplanets: atmospheric signatures and the case of $\mathrm{SO}_{2}$. Astrophys. J. 708, 1162-1167 (2010).

31. Todd, Z. R. et al. Solvated-electron production using cyanocuprates is compatible with the UV-environment on a Hadean-Archaean Earth. Chem. Commun. 54, 1121-1124 (2018).

32. Ranjan, S. \& Sasselov, D. D. Influence of the UV environment on the synthesis of prebiotic molecules. Astrobiology 16, 68-88 (2016).

33. Marion, G. M., Kargel, J. S., Crowley, J. K. \& Catling, D. C. Sulfite-sulfide-sulfatecarbonate equilibria with applications to Mars. Icarus 225, 342-351 (2013).

34. Sutherland, J. D. The origin of life-out of the blue. Angew. Chem. Int. Ed. 55, 104-121 (2016).

35. Ferus, M. et al. High energy radical chemistry formation of HCN-rich atmospheres on early Earth. Sci. Rep. 7, 6275 (2017).

36. Bracher, P. J. Origin of life: primordial soup that cooks itself. Nat. Chem. 7, 273-274 (2015).

37. Wagner, A. J. \& Blackmond, D. G. The future of prebiotic chemistry. ACS Cent. Sci. 2, 775-777 (2016).

38. Schlesinger, G. \& Miller, S. L. Prebiotic synthesis in atmospheres containing $\mathrm{CH}_{4}, \mathrm{CO}$ and $\mathrm{CO}_{2}$. II Hydrogen cyanide, formaldehyde and ammonia. J. Mol. Evol. 19, 383-390 (1983).
39. Cleaves, H. J. II The prebiotic geochemistry of formaldehyde. Precambrian Res. 164, 111-118 (2008).

40. Polstorff, K. \& Meyer, H. Über die einwirkung von cyankalium auf formaldehyde. Ber. Dtsch. Chem. Ges. 45, 1905-1912 (1912).

41. Pasek, M. A. \& Lauretta, D. S. Aqueous corrosion of phosphide minerals from iron meteorites: a highly reactive source of prebiotic phosphorus on the surface of the early Earth. Astrobiology 5, 515-535 (2005).

42. Bryant, D. E. \& Kee, T. P. Direct evidence for the availability of reactive, water soluble phosphorus on the early Earth. H-Phosphinic acid from the Nantan meteorite. Chem. Commun. 2344-2346 (2006).

43. Pitsch, S., Krishnamurthy, R. \& Arrhenius, G. Concentration of simple aldehydes by sulfite-containing double-layer hydroxide minerals: implications for biopoesis. Helv. Chim. Acta 83, 2398-2411 (2000).

44. Mowry, D. T. The preparation of nitriles. Chem. Rev. 42, 189-283 (1948)

45. Pincass, H. Die bildung von calciumcyanamid aus ferrocyancalcium. Chem. Ztg. 46, 661 (1922)

46. Deadman, B. J., Battilocchio, C., Sliwinski, E. \& Ley, S. V. A prototype device for evaporation in batch and flow chemical processes. Green Chem. 15, 2050-2055 (2013).

47. Benner, S. A., Kim, H.-J. \& Carrigan, M. A. Asphalt, water, and the prebiotic synthesis of ribose, ribonucleosides, and RNA. Acc. Chem. Res. 45, 2025-2034 (2012).

48. Wade, N. Making Sense of the Chemistry that Led to Life on Earth. https:// www.nytimes.com/2015/05/05/science/making-sense-of-the-chemistry-thatled-to-life-on-earth.html (2015).

49. $\mathrm{Xu}$, J. et al. A prebiotically plausible synthesis of pyrimidine $\beta$-ribonucleosides and their phosphate derivatives involving photoanomerisation. Nat. Chem. 9, 303-309 (2017).

\section{Acknowledgements}

The authors are grateful to Duncan Guthrie (Vapoutec Ltd.) for the kind loan of a UV photochemical reactor. The authors would like to thank Prof. D. Catling, Prof. D. Sasselov and Prof. J. Grotzinger for helpful discussions. J.D.S. and D.J.R. also thank Dr. T. Rutherford for continued assistance with NMR spectroscopy. D.J.R. would like to thank Dr. R. Labes for technical discussions and guidance. This work was supported by the Medical Research Council (grant no. MC_UP_A024_1009 to J.D.S.), the Simons Foundation (grant no. 290360 to J.D.S.), the EPSRC (grant nos. EP/K00949/1, EP/K039520/1 and EP/M004120/1 to S.V.L.) and ECH Future enabling technologies (FET) ONEFLOW (sponsor ref. 737266 to S.V.L.).

\section{Author contributions}

All of the authors conceived the research and designed and analysed the experiments, though with some focus (J.D.S. and D.J.R. on the prebiotic aspects; S.V.L. and C.B. on the flow aspects). D.J.R. and C.B. conducted the experiments. D.J.R. wrote the paper with input from the other authors.

\section{Additional information}

Supplementary Information accompanies this paper at https://doi.org/10.1038/s41467018-04147-2.

Competing interests: The authors declare no competing interests.

Reprints and permission information is available online at http://npg.nature.com/ reprintsandpermissions/

Publisher's note: Springer Nature remains neutral with regard to jurisdictional claims in published maps and institutional affiliations.

Open Access This article is licensed under a Creative Commons Attribution 4.0 International License, which permits use, sharing, adaptation, distribution and reproduction in any medium or format, as long as you give appropriate credit to the original author(s) and the source, provide a link to the Creative Commons license, and indicate if changes were made. The images or other third party material in this article are included in the article's Creative Commons license, unless indicated otherwise in a credit line to the material. If material is not included in the article's Creative Commons license and your intended use is not permitted by statutory regulation or exceeds the permitted use, you will need to obtain permission directly from the copyright holder. To view a copy of this license, visit http://creativecommons.org/ licenses/by/4.0/

(C) The Author(s) 2018 